\section{MENTOR-VIP and broader capacity building for injury and violence prevention}

Capacity building is one of the most commonly cited needs for advancing injury and violence prevention, particularly in lowincome and middle-income settings. Capacity building needs for injury and violence prevention are broad and varied across the globe, and WHO is actively using a range of capacity building resources to help address these. Here we summarise these efforts and draw particular attention to MENTOR-VIP, as applications for this skills building programme are now being accepted.

Training, Educating and Advancing Collaboration in Health on Violence and Injury Prevention (TEACH-VIP) ${ }^{1}$ is a comprehensive injury prevention and control curriculum developed by WHO and a global network of prevention experts. It was launched in 2005 and has been put into use in training settings in over 90 countries. TEACH-VIP is designed for facilitator-based training. TEACH-VIP E-Learning ${ }^{2}$ was developed and launched in 2010. It is an online training resource developed as a self-paced, self-administered training resource. Within the first year, the TEACH-VIP E-Learning website had received 30000 visits from approximately 11000 unique visitors, with registered users coming from 95 different countries.

In 2012, a major revision to TEACH-VIP resulted in TEACH-VIP 2. TEACH-VIP 2 added a substantial amount of new injury prevention topic areas, refreshed graphics and case examples, and incorporated new data and research. WHO promotes the integration of relevant parts of TEACH-VIP curricula within formal curricula. Most typically, schools of public health, and undergraduate and postgraduate medical and nursing schools have employed these materials. This integration is a long-term win for the injury and violence prevention area, meaning that this historically underserved area will receive greater attention within these areas of study.

In response to requests for focused training packages that address a specific topic or issue, WHO has developed a series of short courses. VIP short courses are available on the WHO website and can be downloaded by end users around the globe. Each VIP short course is a self-contained package including a facilitator's guide to the material, a series of modular training materials built around PowerPoint slides with extensive slide notes, and proposed agendas and interactive exercises. All VIP short courses follow a similar format and are designed to be taught over 25 days. Currently, VIP short courses are available for child injury prevention, child maltreatment prevention, intimate partner and sexual violence prevention, data collection, trauma care system planning and management, and trauma care quality improvement.

In addition to addressing knowledge transfer, it is also important to help people develop their skillsets. For this, WHO has developed the programme known as MENTOR-VIP. ${ }^{3} 4$ MENTOR-VIP is a global mentoring programme for injury and violence prevention in which mentees jointly collaborate with a more experienced mentor for a 12-month period. Email and voice over Internet telephony (eg, Skype and similar applications) are the mainstays of communications. Regular communications are important, as the mentor and mentee typically do not know one another prior to initiating their mentorship, and most often live in different countries. Physical meetings between mentors and mentees do occur, but are not financially supported through the MENTOR-VIP programme, making the role of information technology in facilitating communications all the more critical.
Since the start of MENTOR-VIP in 2007, 63 mentorships have been established on the basis of a competitive application process. The jointly defined collaborative work plans have covered a range of topics and have allowed projects to be brought to fruition with a substantial degree of skills building and bidirectional learning. Evaluations carried out as part of the programme ${ }^{5}$ reveal a high degree of satisfaction and sense of accomplishment from participating in the programme, both from mentors and mentees.

The following quotes are from either mentors or mentees who have participated in the programme over the years:

... a cost-effective way to support junior injury practitioners who come from countries where experts on injury prevention are lacking... (anonymous mentee, China)

My mentee was highly motivated, and it was very rewarding to provide her input as she carved out a strong research programme. Her efforts led to a permanent position in her government. (Corinne Peek-Asa, mentor, United States)

...was an exciting opportunity to learn from an experienced person. I wanted to enhance my writing skills and analyze the problem of different injuries as a burden in the country to advocate for investing in prevention efforts... (Sumit Malhotra, mentee, India)

...programme is innovative globally and provides real opportunities to increase violence prevention capability... (Jonathan Shepherd, mentor, United Kingdom)

...[because of] the success of this initial project I have been able to secure a research fellowship form the Medical Research Foundation to do more extensive research on suicide in South Africa. I would not have had the skill to secure this fellowship without the experience of being in regular conversation with [my mentor]... (Jason Bantjes, mentee, South Africa)

The application window for MENTOR-VIP is approximately 3 months and opens in mid-February each year. Applications will continue to be accepted until 8 May 2015. Individuals interested in applying may find out more by visiting the capacity-building section of WHO's website (http://www.who.int/violence_injury prevention/capacitybuilding). Individuals who would like to apply to be a mentor for the programme can also find out how to do so within the FAQ section for the programme on the WHO website.

\section{R Meddings}

Correspondence to Dr D R Meddings, Department of Violence and Injury Prevention and Disability, 20 Avenue Appia, 1211 Geneva 27, Switzerland; meddingsd@who.int

Competing interests DRM is a staff member of the WHO.

Provenance and peer review Commissioned; internally peer reviewed.

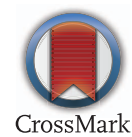

To cite Meddings DR. Inj Prev 2015;21:142.

Inj Prev 2015;21:142. doi:10.1136/injuryprev-2015-041585

\section{REFERENCES}

1 Meddings DR, Knox LM, Maddaleno M, et al. World Health Organization's TEACH-VIP: contributing to capacity building for youth violence prevention. Am J Prev Med 2005;29(5 Suppl 2):259-65.

2 Meddings DR. WHO launches TEACH-VIP E-Learning. Inj Prev 2010;16:143.

3 Meddings DR. MENTOR-VIP: helping develop key skills for injury and violence prevention. Inj Prev 2009;15:68.

4 Hyder AA, Meddings D, Bachani AM. MENTOR-VIP: Piloting a global mentoring program for injury and violence prevention MENTOR-VIP_a global mentoring program for violence and injury prevention. Acad Med 2009;84:793-6.

5 Wadhwaniya S, Meddings D, Gururaj G, et al. E-mentoring for violence and injury prevention: Early lessons from a global programme. Glob Public Health 2015;1-19. 